psychiatric unit an accepted part of the general hospital.

He leaned to the apprentice model of psychiatric training and he was an exemplary trainer. Once a trainee had worked for him, he became the gold standard. His former trainees recall their experiences of him with pleasure and gratitude and remember him personally with affection. He was of distinguished appearance and had considerable energy. Those who worked with him knew that the dryness of manner which he sometimes displayed readily gave way to warmth. He had a sharp sense of humour, and generosity and concern for others underpinned his actions.

In addition to his responsibilities at Stobhill General Hospital, at the request of the procurator-fiscal, over many years he examined persons accused of serious offences. His published work in this area highlighted the importance of alcohol as a major factor in serious offences. His forensic reports, as well as his clinical notes and letters, contained vivid thumbnail sketches, while at the same time being characterised by lucid and felicitous expression and astute judgment. He was one of the most respected Scottish psychiatrists of his generation. He retired in 1976.

He was a private man. In his younge days, he enjoyed sailing - especially off the west coast of Scotland. He maintained an interest in cooking into his later years.
In 1948, he married Mrs Isabelle Canay of Sydney, who died in 1983. In 1987, he married Mrs Margaret Richmond of Oxfordshire and relocated there. She survives him.

Hamilton Frame

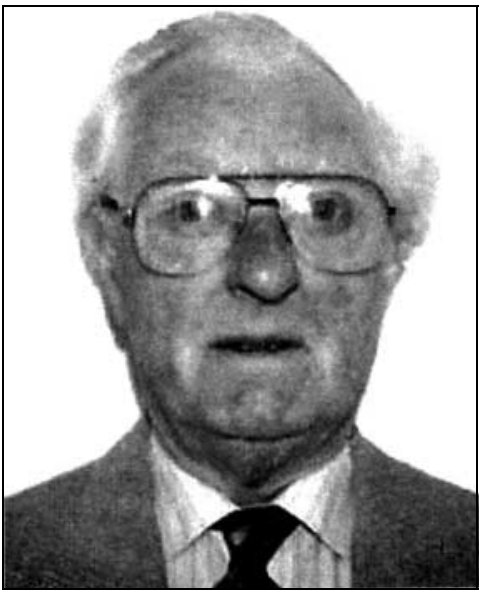

\section{Dr John Richard Theobalds}

Formerly Consultant Psychiatrist, Lancaster Health Authority

John Theobalds was born on 26 July 1923 and died from lung cancer on 28 June 2002.
He received his medical education at Westminster Hospital and qualified from there MRCS Eng., LRCP Lond and MB, BS, Lond., in 1947. After national service, mainly at a military hospital in Egypt, he returned home and worked in general medicine hospitals at Westminster and the Royal Salop Hospital, before deciding on a career in psychiatry.

To this end he served as Registrar at Park Prenett Hospital, Basingstoke and later was appointed Consultant Psychiatrist, Lancaster Health Authority and Medical Director, Priority Services NHS Trust, Lancaster. He gained the DPM. Eng in 1960, was elected MRCPsych in 1971 and proceeded FRCPsych in 1986

John's major interest was in the treatment of alcoholism and drug abuse and he opened Harvey House, currently relocated in the community in Lancaster, and was a founder trustee and committee member of Inward House, a residential therapeutic community for the treatment of drug and solvent misusers.

John's interests were widespread. He loved sport, particularly soccer: he was a lifetime Arsenal supporter and succeeded at one time to be given a trial for Chelsea! He enjoyed reading poetry and listening to music, particularly traditional jazz.

He leaves behind him his second wife, Brenda, whom he married in 1980.

\section{Mohammed Abdul Halim}

\section{reviews}

a review of the Children Act 1989 and the context within which work in a public law court is undertaken. She explores how the Act has caused a considerable growth in the demand for child and adolescent mental health input into the decisionmaking process, both to determine significant harm, particularly in relation to emotional abuse, and also to assist the court in considering future options for the child, young person and family.

This is followed by a discussion of the NHS structure and the contractual arrangements that have led to the bulk of this court work being seen as category 2 work, i.e. outside the usual NHS contract. Brophy considers how this system has resulted in waiting lists and the random uptake of cases when consultants who are willing to do the work have time to do so. Is this a good way to provide vulnerable families with a service? She goes on to discuss the problems that arise when an expert opinion recommends an intervention the local service cannot or will not provide.

The implications for this public law work are considered, given the government proposal for the new consultant contract. If many experts are approaching 